\title{
It's not biology bro: Torture and the Misuse of Science
}

Shane O'Mara

12 School of Psychology and Institute of Neuroscience

13 Trinity College, Dublin

14 shane.omara@tcd.ie

John W. Schiemann

17 Dept. Social Sciences \& History

18 Fairleigh Dickinson University

19 jws@fdu.edu

\section{Abstract}

Contrary to the line in the film Zero Dark Thirty, the CIA's torture program was not based on biology or any other science. Instead, the Bush administration veneered the program's justification with a patina of pseudoscience, ignoring the actual biology of torturing human brains. We reconstruct the Bush administration's decision-making process to establish that the policy decision to use torture took place in the immediate aftermath of the 9/11 attacks without any investigation into its efficacy. We then present the pseudo-scientific model of torture sold to the CIA, show why this ad hoc model amounted to pseudoscience, and then catalog what the actual science of torturing human brains - available in 2001 - reveals about the practice. We conclude with a discussion of how a process incorporating countervailing evidence might prevent a policy going forward that is contrary to law, ethics and evidence. 
2 operative named Daniel has just waterboarded Ammar, who is refusing to provide any

3 information about a Saudi-based terrorist group. When Ammar has recovered sufficiently to

4 listen, Daniel says "It's cool that you're strong. I respect it, I do. But in the end everybody breaks,

5 bro. It's biology" (Boal 2011, 6). Although this Hollywood apologia for the effectiveness of

6 interrogational torture is wrong on many counts, this statement is revealing in two ways.

$7 \quad$ First, there is the implicit assumption that breaking a human being psychologically and

8 physically is the same thing as effectiveness, as getting good intelligence. In other words, there is

9 nothing new here; this is interrogational torture as it always has been and is today, about

10 imposing suffering to "break" human beings. Second, there is the claim that this method of

11 breaking was "scientific," rooted in the biology of the human being, and so fail-safe and sure-

12 fire. The CIA - and the policy makers higher up who approved the torture program - embraced

13 the second claim but denied the first. Indeed, their "scientific" approach to torture was claimed to

14 be something different than simple torture.

15 We challenge both claims, showing that the decision to use torture as well as the so-

16 called 'scientific' approach adopted by the CIA had nothing to do with science and that the

17 program in practice differed little from age-old practices of torture. We also show what the

18 science $o n$ - not "of" - torture actually tells us about both its effectiveness and its brutality. This

19 is all the more important given President Trump's open embrace of torture worse than

20 waterboarding and his nomination of a key participant in the CIA torture program to be the next

21 Director of the CIA.

22 The paper proceeds as follows. The next section reconstructs the decision by the Bush

23 administration to employ torture immediately after $9 / 11$, prior to any research or justifications 
1 based on science. Section two outlines the pseudoscientific justification of the CIA's torture

2 model before showing the program in practice did not correspond to this model in any case.

3 Section three presents what the actual science has to say about the informational effectiveness of

4 torturing human bodies and brains and section four shows how an evidenced based policy brake

5 would have prevented the adoption of CIA torture program.

$7 \quad$ Making Torture Policy

Given that the 9/11 attacks caught the Bush administration by surprise, one might think

9 that it would have taken some time to formulate a policy and evidence-based program on

10 capturing, detaining, and questioning terrorist suspects. Even if one acknowledges that the

11 problem - better intelligence on terrorist plots - was immediately known from that very surprise,

12 an effective policy response might take some time given that the CIA had few case officers with

13 the relevant linguistic and area studies training as well as little institutional experience or

14 structure for detaining and interrogating terrorist suspects trying to hide information (SSCI 2014,

15 38). ${ }^{1}$ CIA officers were trained to debrief possible defectors and to assess individuals for their

16 potential intelligence value, their likelihood of being 'turned', etc., but they were not trained in

17 eliciting information from resisting captives shackled to a chair.

18 This is not to say that the CIA as an institution did not have institutional experience with

19 coercive interrogations (McCoy 2006; Otterman 2007). This experience reflected the

20 interweaving of two influences: CIA-funded 1950s-era research by U.S. and Canadian

21 psychologists and the import of French counterinsurgency techniques in Algeria. In an effort to

\footnotetext{
${ }^{1}$ All references to the SSCI "torture report" use the pdf pages in the original release of the combined Findings and Executive Summary, rather than the page numbers of the originally separated documents.
} 
1 understand the false confessions made during communist show trials and by U.S. airmen

2 captured during the Korean War, the CIA supported research first into drugs and later into the

3 effects of isolation, various forms of deprivation, and stress positions. The results of this research

4 were employed both defensively by the military in an effort to "inoculate" U.S. soldiers in its

5 Survival, Evasion, Resistance, and Escape (SERE) schools and offensively by the CIA in its

61963 counterintelligence interrogation manual (KUBARK 1963) (McCoy 2012, 21). The manual

7 called for "inducing regression ... to [a] weaker level ... required for the dissolution of resistance

8 and the inculcation of dependence" by "prolonged exertion, extremes of heat, cold or moisture,

9 and deprivation or drastic reduction of food or sleep," and "pain," while psychological measures

10 include, among many specific ploys, the general strategies of "threats and fear" (KUBARK

11 1963, 41, 90-93). In the interim decades, both psychology and neuroscience have undergone

12 revolutions in theory, data and experiment, discarding primitive theoretical notions such as

13 'regression' derived from the hydraulic theory of personality proposed by Freudian

14 psychoanalysis.

15 The other influence, what we might call the French Connection, was the influence on the

16 U.S. military and the CIA of French counterinsurgency strategies and tactics against the Algerian

17 national independence movement, particularly during the Battle of Algiers in 1957-1958. That

18 approach involved identifying suspects, launching small operations to capture them, torture them

19 using waterboarding and other techniques immediately for information about other suspects,

20 hideouts, and the like, and then to summarily execute them. General Paul Aussaresses, who

21 helped lead the French efforts, took ten of his junior officers to the U.S. and taught a "Counter

22 Insurgency Officer Course" to U.S. Special Forces at Fort Bragg in late summer 1961 -

23 ironically just as the French had lost the war in Algeria partly as a result of the outrage from 
1 torture and began withdrawing their troops. The course involved a detailed study of the book $L a$

2 Guerre Moderne by one of the architects of the French approach, Roger Trinquier. Aussaresses

3 himself admitted that, among other things, he taught students about "seizure, interrogation, and

4 torture." Students at the school sent the Trinquier book to a CIA official in the White House who

5 later led the CIA's Phoenix Program in Vietnam. ${ }^{2}$

6 Even the 1963 KUBARK manual acknowledged some doubts about the effectiveness of

7 coercive techniques, noting that " $[\mathrm{i}] \mathrm{n}$ fact, most people underestimate their capacity to withstand

8 pain" and "highly motivated" prisoners "have been known to carry out rather complex tasks

9 while enduring the most intense pain." As a result, "[t]he subject finds that he can hold out, and

10 his resistances are strengthened." Moreover, it went on, "'[i]ntense pain is quite likely to produce

11 false confessions, concocted as a means of escaping from distress. A time-consuming delay

12 results, while investigation is conducted and the admissions are proven untrue. During this

13 respite the interrogatee can pull himself together. He may even use the time to think of new,

14 more complex "admissions" that take still longer to disprove. KUBARK [the CIA] is especially

15 vulnerable to such tactics because the interrogation is conducted for the sake of information and

16 not for police purposes" (KUBARK 1963, 90, 93-94). It wasn't, however, until blowback in

171984 following revelations of Nicaraguan Contras' use of a CIA "assassination manual" led to

18 disavowal of coercive interrogation methods by the CIA in revisions to the 1983 version of its

19 KUBARK manual. ${ }^{3}$ Indeed, a top CIA official said as much in a statement to Congress:

20 "inhumane physical or psychological techniques are counterproductive because they do not

21 produce intelligence and will probably result in false answers." (SSCI 2014, 16). In short, by

\footnotetext{
${ }^{2}$ See the documentary Escadrons de la mort - l'école française, at 18:01 - 23:41 https://www.youtube.com/watch?v=8IaA8rTeQRY.

${ }^{3}$ The military did as well, revising its Army Field manual in 1992 (FM 34-52).
} 
1 2001, the CIA had repudiated the teaching of interrogational torture techniques and in any event,

2 "throughout most of its history the CIA did not detain subjects or conduct interrogations" and

3 "therefore had no institutional experience or expertise in that area," though it did occasionally

4 rendition subjects to other countries for torture (OPR 2009, 30-31).

The FBI, of course, did have experience interrogating or interviewing adversaries, both in

6 their law enforcement and counterintelligence (CI) roles, including questioning (and gaining

7 convictions of) Al Qaeda terrorists and foreign spies. Those interrogation methods eschewed

8 coercion for what is often referred to (and sometimes derided) as a "rapport-based" approach, but

9 it also included psychological trickery, deceit, and reliance on cultural and other contextual

10 knowledge. The FBI's experience was deemed less relevant by some since the Bureau's ultimate

11 goal was securing a conviction and probative statements in CI cases, rather than intelligence

12 gathering and monitoring. This criticism is, of course, ironic given torture's long association with

13 false confessions. More importantly, it ignores both the Bureau's substantive expertise

14 (linguistic, cultural, and terrorist-group specific) and institutional experience in ferreting out

15 terrorists and their networks.

16 Although the "all hands on deck" response in the immediate aftermath of 9/11 meant that

17 the FBI did join the CIA in the fight against Al Qaeda in Afghanistan, the Bush administration

18 did not turn to it --- or any "other elements of the U.S. Government with interrogation expertise"

19 --- for crafting a detention and interrogation policy (SSCI pdf p.16). Nor did it "review its [own]

20 past experience with coercive interrogations" (SSCI pdf p.16). Nor is there evidence of serious

21 engagement with the services or agencies of other countries that have dealt with similar problems

22 over many decades without torturing. 
In fact, the decision to use coercion was almost instantaneous. Within three days of the

2 attacks, Cofer Black, Chief of the Counterterrorism Center (CTC) was requesting input on where

3 to locate CIA-operated detention centers abroad, where they would be insulated from

4 international law and human rights groups such as the International Committee of the Red Cross.

5 The request went out on September 14, 2001. Two days later Vice President Cheney stated in an

6 interview on NBC that

7 "We also have to work, though, sort of the dark side, if you will.... A lot of what needs to be done here will have to be done quietly, without any discussion, using sources and methods that are available to our intelligence agencies, if we're going to be successful. That's the world these folks operate in, and so it's going to be vital for us to use any means at our disposal, basically, to achieve our objective" (NBC 2001, our emphasis).

13 Nevertheless, this is an early indication that the administration was unencumbered by concerns

14 about limits and restraints. On September $17^{\text {th }}$, the day after Cheney's interview, President Bush

15 incorporated Black's requests into a Memorandum of Notification giving the CIA long term

16 blanket authority to employ deadly force against as well as capture, rendition to other countries,

17 and itself detain terrorist suspects around the world (SSCI 2014, 16; Mayer 2008, 42-43;

18 Woodward 2002, 76). Although the MON itself did not discuss interrogations, the CIA was 19 already working on it.

“In the weeks after 9/11,” a CIA psychologist, Kirk Hubbard, brought James Mitchell, a

21 retired SERE psychologist in the same "informal network of military and civilian psychologists

22 and psychiatrists with shared interests in psyops [psychological operations], Special Forces

23 selection, resistance training, and the reliability of "humint" (human intelligence)" as Hubbard, to 
1 the attention of higher-ups in the CIA (Bloche 2011, 136, 135). Although he had no "experience

2 as an interrogator, nor ... specialized knowledge of al-Qa'ida, a background in counterterrorism,

3 or any relevant cultural or linguistic expertise," Mitchell believed he could reverse engineer the

$4 \quad$ SERE techniques into interrogation techniques that would elicit accurate and valuable

5 information. "By the end of November 2001," the CIA was already exploring legal defenses for

6 outright torture relying on the ticking-bomb scenario (SSCI 2014, 45-46). At the end of 2001 the

7 CIA asked Mitchell to analyze the "Manchester Manual," a document seized in a raid in Britain

8 that described alleged al-Qaeda resistance techniques. ${ }^{4}$ Mitchell asked Jessen, a senior SERE

9 psychologist, to help him prepare the assessment.

They completed their memo, titled "Recognizing and Developing Countermeasures to Al

11 Qaeda Resistance to Interrogation Techniques: A Resistance Training Perspective," by February

122002 and it was circulated within the top levels of the CIA (SSCI 2014, 47, fn.57; Warrick and

13 Finn 2009). Around this same time, Mitchell, perhaps with Jessen, wrote "Interrogator Training,

14 Lesson Plan, Title: A Scientific Approach to Successful Interrogation” (SSCI 2014, 47, fn.58).

15 Meanwhile, Jessen had, “[b]y early March, ... developed slide presentations, titled "Al Qaeda

16 Resistance Contingency Training" and "Exploitation," [which] included slides on "isolation and

\section{${ }^{4}$ Available at: \\ https://www.justice.gov/sites/default/files/ag/legacy/2002/10/08/manualpart1_1.pdf. It is worth}

noting that while the handbook has been described as an Al Qaeda document, it is clear that it was written by a smaller group opposed to the Egyptian regime (Eichenwald 2012, 545-552). Crafting an interrogation policy around this document was, to quote Eichenwald, "like the Pittsburgh Steelers prepar[ing] for a game against the Dallas Cowboys by reviewing the playbook from Tuscaloosa High School” $(2012,551)$. 
1 degradation," "sensory deprivation," "physiological pressures" (a SERE euphemism for beatings

2 and other physical abuse) and "psychological pressures" (Bloche 2011, 139). These documents

3 are classified, but it is known that Mitchell and Hubbard met several times between December

42001 and March 2002 with the psychologist Martin Seligman to discuss his theory of "learned

5 helplessness" (Bloche 2011, 1430-141). We discuss this further below, but the point for now is

6 that inducing learned helplessness, like the SERE techniques, involved torturing detainees.

7 Indeed, between September and December 2001 the Office of Legal Counsel in the Justice

8 Department had been crafting what would later be known as the "torture memos"' denying the

9 protections of Geneva to captured Taliban fighters in Afghanistan as well as suspected Al Qaeda

10 operatives captured there and elsewhere around the world (Cole 2009). Thus, the die for coercion

11 was already cast and Hubbard, Mitchell, and Jessen would get the chance to implement their

12 program just a few months later, after Abu Zubaydah was captured in Pakistan at the end of

13 March, 2002.

14 Although Zubaydah was already providing valuable information to two FBI agents,

15 Mitchell was sent to the CIA's secret prison in Thailand to take over the interrogation. At about

16 the same time, Mitchell proposes 12 tortures, all but two of which would be approved by the

17 Justice Department and the CIA as the "enhanced interrogation techniques on August 2, 2002 in

18 one of the torture memos. On August 4, after having been left in isolation with no questions put

19 to him for 47 days after Mitchell took over, Abu Zubaydah was dragged out of his cell, and

20 started the round the clock torture for the next three and one-half weeks (Schiemann 2014, 3). As

21 Counter Terrorism Center Director Cofer Black put it on September 26, 2002 when speaking at a

22 Congressional hearing "the gloves [had] come off." In short, rather than rely on traditional

23 methods of interrogation or research the effectiveness of other methods, multiple sources all 
1 reveal that the Bush administration, including both the CIA and the military, "reversed two

2 centuries of official policy by adopting torture for interrogation purposes" without investigating

3 its efficacy for intelligence gathering (Lightcap and Pfiffner 2014, 4; SSCI 2014, 46).

4

\section{The Pseudoscience of Torture}

6 The "scientific" model of interrogational torture sold by Mitchell and Jessen was a

7 patchwork stitched together from three sources: the CIA's own cold war interrogation model

8 represented by it's 1963 KUBARK manual, reverse-engineering military survival school (SERE)

9 training, where Mitchell and Jessen both worked, as well as psychologist Martin Seligman's

10 theory of "learned helplessness." Troubled by confessions made under duress first by victims of

11 Soviet show trials and later by US POWs to the Chinese and North Korean military in the

12 Korean War, the United States responded by researching various “mind-control techniques,"

13 including drugs, hypnosis, sensory deprivation, and psychological and physical coercion such as

14 sleep deprivation and stress positions (McCoy 2006; Otterman 2007). The findings were used

15 both offensively and defensively, offensively in the development of an interrogation manual used

16 not only by the CIA, but also by client militaries and intelligence agencies in Latin America, and

17 defensively in the different SERE schools for members of the US military (KUBARK 1963;

18 Otterman 2007). A retired SERE psychologist, Mitchell was aware of learned helplessness from

19 SERE instructor manuals emphasizing the danger of inducing learned helplessness (Bloche 2011,

20 128-131). Indeed, more than simply aware, another former SERE instructor who knew Mitchell

21 said that "Learned Helplessness was [Mitchell's] whole paradigm" (Mayer 2008, 164). It played

22 such an important role in his thinking in fact that he and CIA psychologist Kirk Hubbard 
1 arranged several meetings with Seligman himself, seeking ways to apply it to the SERE

2 techniques Mitchell was reverse-engineering for the CIA (Bloche 2011, 140-141).

The result of this grafting "learned helplessness" onto SERE techniques, Mitchell

4 claimed, was a "[s]cientific [a]pproach" to interrogating terrorist suspects (Senate 2014, 47,

5 fn.58). According to this two-phase approach, the combination of detention conditions such as

6 temperature, light, food, and auditory manipulation on the one hand and various "enhanced

7 interrogation" tortures on the other would induce a state of "learned helplessness" in its victims,

8 causing them to move from resistance to compliance. This successful interrogation phase would

9 be followed by a "debriefing" phase in which suspected terrorists would be questioned using

10 more traditional rapport-based methods. There are multiple problems with this model, from the

11 its theoretical underpinnings through the "data," both adduced and ignored, and the actual

12 practice of the program.

13 The theory behind the 1963 CIA interrogation (KUBARK) manual and the SERE

14 program was based on 1950s era psychological research by Harold Wolff, Albert Biderman,

15 Lawrence Hinkle, Malcolm Meltzer, I.E. Farber, and others. Biderman, for example, sought to

16 ascertain why some U.S. Korean War POWs had made absurd confessions. One of his

17 conclusions was that the communist techniques first induced compliance via sensory

18 manipulation, sleep deprivation, and stress positions rather than direct physical assaults, and then

19 molded that compliance into confessions. The techniques induced compliance by creating

20 "despair," "debility, dependency and dread," and "regression" (Bloche 2011, 1334, 1340, 1349;

21 Farber et al 1957; KUBARK 1963, 83, 112-113).

22 What is often overlooked, however, is that Biderman readily acknowledges that "the final

23 outcomes [of prisoner behavior] were distributed through the broad range of intermediate 
1 possibilities" in between total compliance and total resistance ... that [i]n almost all, resistance

2 was the dominant ingredient," and none behaved in "complete accordance" with their communist

3 captors (Biderman 1957, 625, 628). In another paper Biderman notes that while his focus is on

4 the cases where interrogation was effective, he "does not wish to convey an exaggerated

5 impression of its potency" for [m] ost Air Force repatriates, on the contrary, claim considerable

6 success in evading, deceiving, and delaying their interrogators. Further, over two-thirds of the

7 repatriates, in anonymous replies to a mail questionnaire, expressed the opinion that such

8 information as the Communists did elicit was such as to have little effect, if any, on military

9 operations" (Biderman 1960, 126). Moreover, Biderman emphasizes "that the distinction

10 between inducing compliance and shaping compliance is purely an analytic division. The two

11 kinds of methods are not independent of one another nor separate in time" (Biderman 1957,

12 618). When one also notes Biderman's insistence that the same methods were also used to gain

13 compliance for false confessions as "for eliciting factual intelligence information," the value of

14 the distinction in practice breaks down further (Biderman 1957, 618). In short, using Biderman's

15 exploration of a few cases of limited success to design an interrogation program is like looking

16 for factors that allowed the tiny fraction of people who survived falls from airplanes without a

17 parachute rather than simply issuing parachutes.

18 The second part of the theory veneering the CIA program with a patina of science was the

19 concept of "learned helplessness," though Mitchell's fascination with it did not translate into any

20 understanding of what the theory of learned helplessness actually entailed. Learned helplessness

21 has its historical origin in Pavlovian conditioning procedures, but using unpredictable and

22 uncontrollable aversive stimuli (typically electric shock), rather than rewarding and predictable

23 appetitive stimuli (such as food reward). Animals exposed repeatedly to uncontrollable and 
1 unpredictable electric shocks showed a characteristic syndrome of apathy, akinesis and

2 amotivation, once they learned their situation was inescapable. Learned helplessness was the

3 name give to this behavioral syndrome, and in its clinical application to humans was devised to

4 provide a theory for the development of major depressive disorder (MDD) in humans.

MDD is disabling neuropsychiatric condition characterized by 'a depressed mood or a

6 loss of interest or pleasure in daily activities consistently for at least a two week period. This

7 mood must represent a change from the person's normal mood; social, occupational, educational

8 or other important functioning must also be negatively impaired by the change in mood.' (DSM

$94 \mathrm{r})$ Additionally, MDD comes with a panoply of well-recognized impairments of cognition,

10 including catastrophizing, excessive rumination with a preponderantly negative bias, a

11 pessimistic explanatory style and deficits in learning and memory. Clinically, learned

12 helplessness is associated with a loss of perceived control over major and minor life events,

13 resulting in the symptomatology of MDD (Otte et al., 2016).

14 It is unclear how learned helplessness could ever have been thought to be a viable theory

15 for interrogation; the clinical literature is quite clear regarding the typical MDD syndrome (e.g.

16 Bortolato et al., 2014), and some reflection and consultation of the clinical psychological literature

17 would have revealed its inadequacy in the domain of interrogation. In fact, the Farber et al piece

18 quoted in the KUBARK manual notes that the result for many is permanent apathy; they never

19 move to compliance (Farber et al 1957, 275-276). Mitchell himself notes the danger in a

20 deposition he was forced to provide as part of a lawsuit against him by a victim of his program:

21 "profound helplessness that leads to depression, passivity and withdrawal" (Salim v. Mitchell

22 2015, p.77, lines 18-20). And yet, the psychologically primitive view seems to have been

23 adopted that inducing a state of learned helpless would equal a state of compliance which would 
1 facilitate information elicitation. The idea that inducing the state of learned helplessness might

2 result in a loss of information, because the brain systems regulating learning and memory are the

3 self-same systems affected by the extreme stressors involved in learned helplessness, seems

4 never to have occurred to those who devised the programme.

5 Whereas the Mitchell/CIA model dressed up the first, compliance-inducing phase in the

6 garb of psychological science, even this pretense was dropped for the second phase: detecting

7 deception from supposedly compliant detainees. None of the released documents reference a

8 scientific theory on separating accurate from inaccurate information comparable to the references

9 to "learned helplessness." The likely reason is that the research on detecting deception by

10 scrutinizing nonverbal cues "present[s] a bleak picture" (Vrij et al 2017, 939-941). In the face of

11 this substantial research to the contrary, Mitchell simply claimed in his memoir that he could

12 identify "poker tells, or body language that would tip [interrogators] off to when he was telling

13 the truth and when he was being deceitful" (Mitchell and Harlow 2016, 58). The scientific

14 consensus is that this is not so, and the cues that people use for detecting deception are faint and

15 unreliable (Vrij, 2008), and this literature is unreferenced in Mitchell's memoir. It has also been

16 claimed that Mitchell and the other interrogators could detect falsehoods by immediately

17 checking information. Not only does the Senate report provide abundant evidence of false

18 information, but Mitchell himself told participants at a CIA-organized psychological conference

19 on detecting deception "if we are interviewing a terrorist, how can we tell if he is lying"

20 (Hoffman 2015, 167-169). This conference took place in July 2003, nearly a year after Mitchell

21 had personally tortured Abu Zubaydah and just a month after Khalid Sheikh Mohammed (KSM)

22 had retracted information on a plot he had provided to stop being waterboarded (Schiemann

23 2015, 241-242; SSCI 2014, 459-460). 
In reality, therefore, what was applied to was no more than a folk or lay theory of

2 neuropsychological functioning to information retrieval from a human source (O’Mara, 2009), a

3 theory which would collapse under the slightest contact with empirical reality, and which would

4 not, if elaborated as a theory, pass any form of objective peer review. It is thus unsurprising that

5 the only "data" for the effectiveness of the CIA model was anecdotal, based on Mitchell and

6 Jessen's experience in the SERE program. What is more, that experience was supervising mock

7 interrogations carefully controlled to avoid actually inducing learned helplessness, rather than

8 personal experience conducting actual interrogations where the goal was to fully induce it

9 (Bloche 2011, 140). Not only was there no systematic data on the effectiveness the CIA model,

10 neither the CIA nor Mitchell/Jessen conducted any review of the relevant psychological,

11 neurobiological, or neuroscience literature on the possible negative cognitive and memory-recall

12 effects of the techniques they proposed. As discussed further below, even a cursory review of

13 this literature would have called claims of effectiveness into question.

14 Whatever the problems besetting Mitchell and the CIA's theory, it did not function that

15 way in practice. Instead, the program operated essentially no differently than other

16 interrogational torture programs. First, there was little initial attempt to ascertain compliance,

17 with most of the detainees subjected to the most severe methods having been subjected to them

18 "immediately after being rendered to CIA custody" (SSCI 2014, 9). Indeed, this was despite the

19 fact that some had either already indicated to the CIA their desire to cooperate or even had

20 already provided information prior to their rendition (SSCI 2014, 9-10, 103, 459). Second, the

21 stepwise (if generally rapid) escalation of the torture's severity based on detainee answers

22 differed little from other accounts of torture, both historical and contemporary. Nor was there

23 some magic moment when compliance was reached and then maintained thereafter. Many 
1 detainees (e.g. Abu Zubaydah, KSM, Abu Faraj al-Libi, Ammar al-Baluchi, and Khalid bin

2 Attash) who were supposedly compliant were later found to have provided false information or

3 left out important information (Schiemann 2015, 237-238). Indeed, about one in six CIA

4 detainees subjected to the harshest treatment would never become "compliant" insofar as they

5 provided no intelligence whatsoever (SSCI 2014, 9, 25). ${ }^{5}$ With others, the CIA couldn't figure

6 out whether he was compliant or not. Abd al-Rahim al-Nashiri, for example was waterboarded at

7 least three times at the secret prison in Thailand before being transferred to the Polish black site

8 where he was tortured with EITs during four periods: December 5-8, 2002, December 27, 2002,

9 to January 1, 2003, January 9-10, 2003, and January 15-27, 2003. Jessen himself would

10 conclude nearly two years later that al-Nishiri provided "essentially no actionable information"

11 and "the probability that he has much more to contribute is low" (SSCI 2014, 99).

12 In short, the torture model sold to the CIA for over $\$ 80$ million was pseudoscience in

13 both method and substance. The pseudoscience amounted to a presumption of well-founded

14 theory and knowledge, in particular that inducing states of dependency and learned helplessness

15 would induce compliance, which would in turn allow the source to subsequently reveal otherwise

16 withheld information: this would be the royal road to truth-finding. Instead it served to varnish a

17 program of interrogational torture that differed little from its historical predecessors.

\section{The Science on Torture}

Thus, by choosing torture, however much adorned with the trappings of science, policy-

21 makers in the Bush administration ignored both the long history of torture and the study of that

22 history from multiple perspectives (Lea 1973; Peters 1999; Langbein 1978; Rejali 2007; Mialon

\footnotetext{
${ }^{5}$ This is based on seven out of 39 detainees subjected to EITs. Two of these, however, were innocent and so presumably in the group of seven.
} 
1 2011; Schiemann 2015; Baliga and Ely 2016; O’Mara, 2009, 2015). But they ignored more than

2 history and social science. They also ignored the science of stress, sensory deprivation, and other

3 torture-like stimuli on animals and humans available in the psychological, neurobiological, and

4 neuroscience literature.

5 This actual science overwhelmingly demonstrates that interrogational torture fails as a

6 veridical, reliable and predictable information-gathering and information-discovery practice

7 (O’Mara 2015). Torture fails for predictable reasons rooted in our deepest cognitive,

8 neurobiological and physiological function. The information sought from the source by the

9 torturer is, by definition, stored in the cognitive and memory systems of the brain of the source:

10 it can be nowhere else. By definition, interrogators want sources to retrieve explicit, long-term

11 memories. Explicit memory is defined as memory for past, personally-experienced facts and

12 events extending over at least one sleep-wake cycle (and beyond). Memories also include

13 intentions for future action. A non-exhaustive list of information (memories) sought from the

14 source includes where they were; what they were doing; what they were planning to do; their

15 social network; monetary and other resourcing; the particulars of their world view; their

16 reasoning regarding world events; their mental health; their salient intellectual, social, religious,

17 familial commitments; their general mind-set; potential personality problems (narcissism,

18 egoism, grandiosity, for example); the degree of their sublimation to their cause; the extent to

19 which they are knowledge-rich or knowledge-poor about the world; and much more besides.

20 Much is now known about how the brain supports cognitive, executive, mnemonic and

21 affective function. Similarly, much is known about likely optimal means and methods for

22 probing the contents of cognition and memory. A network of mutually-interacting and co-

23 regulating brain regions support these functions; moreover, these brain regions can easily 
1 compromised by stress, infection, injury and the limitations of their intrinsic design features. The

2 brain is, for example, a limited storage entity, with the consequence that human memory does not

3 function like a video recorder, faithfully recording the events of the past. Human explicit

4 memory is dynamic, preserving largely the gist of experienced events, and is subject to revision

5 through subsequent experience.

6 Human memory is fragile and labile, with a well-defined forgetting curve. Moreover,

7 recollective acts can change memories of the past, and leading questions can cause people to

8 recall events that have not happened to them. Within the brain, explicit memory is supported by

9 interactions between the hippocampal formation, prefrontal cortex and the anterior thalamus.

10 Interactions between these regions, combined with regular sleep, are required for the encoding,

11 storing and retrieval of memories, as well as for normal cognitive function (Aggleton et al.,

12 2010).

13 The stressor states employed during interrogational torture involve assaults on the core

14 functioning of brain and body: they include sleep deprivation, caloric restriction, hypoxia and

15 predator threat. Predator threat can arise directly (through the repeated near-death and revival

16 experience that occurs during waterboarding) or vicariously (through death threats to family

17 members, other loved ones, or community members, for example); predator threat is perhaps the

18 most severe stressor living organisms can face. Interrogational torture as a theory posits that

19 imposing these extreme stressor states facilitates the release of information withheld by the

20 source: a deliberate program, carefully calibrated and imposed by appropriately skilled and

21 trained practitioners, torture will cause the detainee to reveal the contents of their long-term

22 memories. Further, the source will reveal these memories in a reliable, veridical and replicable

23 fashion - without affecting the rate at which confabulation, misdirection, or false recall will occur 
1 - either within or between interrogational torture sessions. However, this folk model of

2 neuropsychological function fails, and fails dramatically, on contact with what is known about

3 the brain. The brain operates within a narrow adaptive and homeostatic range: brain temperature

4 must be maintained in a narrow range, and a continuous supply of oxygen and nutrients are also

5 required or brain structure and function will be compromised, perhaps irreversibly.

6 The extreme stressors employed during torture force the brain away from this narrow,

7 adaptive range. These stressors cause dysregulation across a wide range of organ systems in

8 brain and body. Predictable changes in the brain's structure and function occur when these

9 stressor states are imposed. The stressors employed result in tissue loss in the brain regions

10 supporting memory (particularly of the hippocampal formation), resulting in enduring deficits in

11 explicit memory. By contrast, the volume of the amygdala - the principal brain region concerned

12 with the processing of fear and threat-related information - increases in size under chronic and

13 severe stress. A resulting and persistent state of hypervigilance and lowering of startle reflexes

14 ensues, as seen in post-traumatic stress disorder and related conditions. Brain regions supporting

15 intention and general behavioral control (the prefrontal cortices) become less responsive as a

16 result of chronic and extreme stress, resulting in deficits in directed and intentional recall of

17 memories (Roozendaal et al., 2009).

18 Numerous studies of these stressors in combat and elite soldiers, certain neuropsychiatric

19 patient groups (including those previously subject to torture), athletes, normal populations and

20 animal models find these stressors substantially compromise memory, mood, and cognitive

21 function. Sleep deprivation is a widely employed method of 'white' torture: the consensus is that

22 sleep deprivation is possibly the most effective tool for causing chronic and substantial deficits in

23 cognition, mood and memory. The effect of sleep deprivation is in direct proportion to the dose 
1 of sleep deprivation imposed. The sleep deprived show substantial deficits in psychomotor and

2 general cognitive function (they are also more likely die in auto accidents, for example); the

3 sleep deprived manifest profound problems in explicit memory, with deficits in the encoding,

4 consolidation and retrieval of memory. They are much more likely to make false confessions in

5 laboratory situations. Supervening states of pain reliably impair cognition, memory and mood in

6 volunteers, chronic pain patients and in animal models. The evidence all points in the same

7 direction: extreme stressors of the type used during torture impair cognition, memory and mood

8 in all of their phases. Hence, the historic and contemporary veridical information yield from

9 torture has been insignificant, while the false positive rate, and false confession rate has been

10 remarkably high. The extreme stressor states employed during torture need to be seen for what

11 they are: utterly inimical to reliable and veridical information gathering and information

12 discovery. Better and more reliable ethical methods are available, using approximately skill-set

13 of a skilled clinician; these skills are ethical, transferable and reliable, and ensure the minimal

14 contamination of the information supplied by the source (O'Mara 2018).

15 The past ten or so years have seen the development of a remarkable evidence-base on

16 information elicitation - even from the unwilling - using non-coercive means using what is now

17 generically referred to as 'investigative interviewing' (Bull, 2014). Prior experience from the

18 Second World War showed across a variety of intelligence services the futility of torture, and

19 moreover, the difficulty in getting policy makers to pay attention to intelligence contrary to their

20 beliefs (Hastings, 2015). Stalin's refusal to listen to the evidence of the imminent Nazi invasion

21 is a particularly salient example. What has become known as the Scharff Technique - a

22 conversational style of interviewing with open-ended questioning, conducted in a situation of

23 respect and active listening - is at the core of many modern investigative interviewing methods 
1 (e.g. Meissner et al., 2015). Similarly, there have been remarkable developments in the detection

2 and understanding of lies and deception during investigative interviewing (Vrij, 2008). Finally,

3 there have been a remarkable series of field and captive based studies of terrorist interrogations

4 focused on information elicitation and the minimizing of counter-interrogation tactics (Alison

5 and Alison, 2017). These developments are based on modern theory in the brain and behavioral

6 sciences, are ethical, trainable and transferable, and provide a remarkable evidence base for

7 future policy. The United Nations Special Rapporteur on Torture in a major report to the General

8 Assembly of the UN has advocated the use of a universal investigative interviewing protocol

9 based on these other evidence-based methods to eliminate the false convictions resulting from

10 confession evidence (Mendez, 2016).

\section{Evidence-based policy brakes}

12 Deciding any a major policy change - and especially one as serious and morally, legally,

13 and ethically fraught as is torture - should be undertaken only after placing the appropriate

14 evidence-based policy standards in place. This would ensure that if a policy were to be enacted

15 that the evidence, legal principles, and ethical review in favor of the policy is so strong that it can

16 be defended easily and rigorously. However, in the case of the CIA program, there is no

17 evidence that the experience of other nation states was solicited. Similarly, there is no evidence

18 of a rigorous exploration of the historical use of torture. Internationally, the evidence suggests

19 that torture is most frequently employed for the elicitation of confessions - which are probative

20 in many legal systems. There has been a marked evolution away from confession-based legal

21 processes in many Western European jurisdictions. The quashing of many unsafe and

22 unsatisfactory confession based convictions for terrorist offences in the United Kingdom during

23 the 1970's is an especially germane example. 
Where, therefore, was the evidence-based policy brake? A policy brake sets a threshold

2 for a policy decision and action to meet a particular evidential moral and legal basis. It provides

3 the necessary back-stop to ensure a policy cannot go ahead if the countervailing evidence is

4 against any likelihood of success. There is little by way of public evidence that a discussion and

5 a well-founded set of policy guidelines with the appropriate and necessary evidence-based policy

6 brake was ever considered. To take a salient example: sleep-deprivation was employed as a

7 method of coercive interrogation. O’Mara (2015) reviewed the evidence available on the effects

8 of sleep deprivation at the time the memos were written, and concluded that: 'contrary to the

9 thinly researched and poorly discussed impression provided by the memos, there was available a

10 large and extensive literature about sleep deprivation in healthy volunteers, in chronic

11 insomniacs, and in shift workers and other occupational groups. The literature of this time

12 converges on a strong and consistent message: that sleep deprivation causes deficits across a

13 wide set of affective, cognitive, physiological, and immune functions and that the effects are

14 dose dependent. The more sustained the period of sleep deprivation, the greater the effects.' In

15 other words, no good faith attempt was made to review the likely effects of sleep deprivation: if

16 one had been conducted, it would have recommended against the use of sleep deprivation

17 because of the widespread deleterious effects of this very profound stressor on brain and body.

\section{Conclusions}

The 'Enhanced Interrogation Technique' programme provides many object lessons for

20 students of government policy formation, especially at the intersection of the life sciences and

21 politics. The information sought from the source is, by definition, located in the memory system

22 of the source. Substantial evidence exists from multiple disciplines - law, neuroscience,

23 psychology, among others - showing the extreme fragility and malleability of human memory 
1 and human self-reported and generated testimony. No serious, good-faith, effort was made to

2 engage with this large evidence base; instead, policy was created around a pre-existing base of

3 assumptions that themselves were never interrogated and dissenting voices ignored (e.g.

4 Zelikow, 2012). Furthermore, no policy brake was ever instituted to allow the pre-emptive

5 aborting of a policy that was likely to fail, given the evidence that was available.

6

7 References

8 Aggleton, JP O’Mara, SM. Vann, SD, Tsanov, M., Wright, N, Erichsen, J, (2010). Reciprocal

9 Hippocampal - Anterior Thalamic Pathways For Memory: A Network Of Direct And

10 Indirect Actions. European Journal of Neuroscience, 12, 2292-2307.

11 Alison L, Alison E. Revenge versus rapport: Interrogation, terrorism, and torture. Am Psychol. 2017;72(3):266-277.

13 Baliga, Sandeep, and Jeffrey C. Ely. "Torture and the commitment problem." The Review of Economic Studies. 83, 4 (2016): 1406-1439.

15 Biderman, Albert D. 1957. "Communist Attempts to Elicit False Confessions from Air Force 16 Prisoners of War." Bulletin of the New York Academy of Medicine. 33, 9 (September): $17 \quad 616-25$.

18 Biderman, Albert D. 1960. "Social-Psychological Needs and "Involuntary" Behavior as Illustrated by Compliance in Interrogation.” Sociometry, 23, 2 (June): 120-147.

Bloche, M. Gregg. 2011. The Hippocratic Myth: Why Doctors Are Under Pressure to Ration Care, Practice Politics, and Compromise their Promise to Heal, New York: St. Martin's Press. 
1 Bortolato B, Carvalho AF, McIntyre RS (2014). Cognitive dysfunction in major depressive disorder: a state-of-the-art clinical review. CNS Neurol Disord Drug Targets 13(10):1804-18.

Bull R (Editor). Investigative Interviewing. Springer-Verlag: New York; 2014.

Cole, David. 2009. Torture Memos: Rationalizing the Unthinkable. New York: The New Press.

Diagnostic and Statistical Manual of Mental Disorders (DSM) American Psychiatric Association Washington, DC: American Psychiatric Association. 1994. ISBN 978-0-89042-065-2.

Eichenwald, Kurt. 2012. 500 Days: Secrets and Lies in the Terror Wars. New York: Simon and Schuster.

Farber, I. E., Harry F. Harlow and Louis Jolyon West. 1957. "Brainwashing, Conditioning, and DDD (Debility, Dependency, and Dread).” Sociometry, 20, 4 (December): 271-285.

Hastings M. The Secret War: Spies, Codes and Guerrillas, 1939-45. London: William Collins; 2015. Hoffman. 2015. Hoffman, David H., Carter, D. J., Lopez, C. R. V., Benziller, H. L., Guo, A. X., Latifi, S. Y., Craig, D. C. (July 2, 2015). Report to the Special Committee of the board of directors of the American Psychological Association: Independent review relating to APA ethics guidelines, national security interrogations, and torture. Chicago, IL: Sidley Austin LLP.

KUBARK. 1963. KUBARK Counterintelligence Interrogation. Washington D.C.: Central Intelligence Agency. Available at: http://www.gwu.edu/ nsarchiv/NSAEBB/NSAEBB122/index.htm\#kubark.

Lightcap, Tracy and Pfiffner, James P. 2014. Examining Torture: Empirical Studies of State Repression. New York: Palgrave Macmillan. 
1 Mayer, Jane. 2008. The Dark Side. New York: Doubleday.

2 McCoy, Alfred W. 2012. Torture and Impunity: The U.S. Doctrine of Coercive Interrogation. Madison, WI: University of Wisconsin Press.

4 McCoy, Alfred W. 2006. A Question of Torture: CIA Interrogation, from the Cold War to the War on Terror. New York: Henry Holt and Company.

6 Meissner C, Kelly C, Woestehoff S. Improving the Effectiveness of Suspect Interrogations. Ann Rev Law Soc Sci. 2015;11(1):211-233.

8 Méndez, Juan E (2016). Interim report of the Special Rapporteur on torture and other cruel,

9 inhuman or degrading treatment or punishment UN Document A/71/298 [Internet].

10 Available from: https://digitallibrary.un.org/record/839995? $\ln =e n$

11 Mitchell, James E. and Bill Harlow. 2016. Enhanced interrogation: Inside the minds and 12 motives of the Islamic terrorists trying to destroy America. New York: Crown Publishing 13 Group. NBC. 2001. "Text: Vice President Cheney on NBC's 'Meet the Press'.” The Washington Post. Sunday, Sept. 16, 2001. motivating 'enhanced and coercive interrogation techniques'. Trends in Cognitive Science, 13, 497-500. O'Mara, SM (2011). On the Imposition of Extreme Stressor States (Torture) to Facilitate the Release of Information From Memory: A Baleful Consequence of Folk Cognitive Neurobiology. Zeitschrift für Psychologie/Journal of Psychology, 219, 159-167.

O'Mara, S.M. (2015). Why Torture Doesn't Work: The Neuroscience of Interrogation. Cambridge, Mass: Harvard University Press. 
O'Mara, SM (2018). The Captive Brain: Torture and the Neuroscience of Humane Interrogation. QJM: Monthly Journal of the Association of Physicians. https://doi.org/10.1093/qjmed/hcx252 OPR. 2009. "Investigation into the Office of Legal Counsel's Memoranda Concerning Issues Relating to the Central Intelligence Agency's Use of “Enhanced Interrogation Techniques" on Suspected Terrorists. Department of Justice, Office of Professional Responsibility. Washington D.C.: Office of Professional Responsibility, Department of Justice.

(

Otterman, Michael. 2007. American Torture: From the Cold War to Abu Ghraib and Beyond Melbourne: Melbourne University Publishing.

Otte, C., Gold, S. M., Penninx, B. W., Pariante, C. M., Etkin, A., Fava, M., ... \& Schatzberg, A. F. (2016). Major depressive disorder. Nature Reviews Disease Primers, 2, 16065.

Roozendaal B, McEwen B, Chattarji S. Stress, memory and the amygdala. Nature Rev Neurosci. 2009;10(6):423-433. doi: 10.1038/nrn2651.

4

Salim v. Mitchell. 2015. Suleiman Abdullah Salim, Mohamed Ahmed Ben Soud, Obaid Ullah (as personal representative of Gul Rahman), v. James Elmer Mitchell and John "Bruce" Jessen, Complaint. Civil Action No. 2:15-CV-286-JLQ. United States District Court for the Eastern District of Washington. October 13, 2015. Available at: https://www.aclu.org/legal-document/salim-v-mitchell-complaint.

Schiemann, John W. 2015. Does Torture Work? New York: Oxford University Press. SSCI (Senate Select Committee on Intelligence). 2014. United States Senate Select Committee on Intelligence Study of the Central Intelligence Agency's Detention and Interrogation Program, Findings and Conclusions, Executive Summary. Washington D.C.: United States Senate. Availiable at: http://www.intelligence.senate.gov/study2014/sscistudy1.pdf. 
1 Vrij, A. Detecting Lies and Deceit: Pitfalls and Opportunities John Wiley \& Sons (2008)

2 Vrij, Aldert, Christian A. Meissner, Ronald P. Fisher, Saul M. Kassin, Charles A. Morgan III, 3 and

4 Steven M. Kleinman. 2017. "Psychological Perspectives on Interrogation." Perspectives on Psychological Science. 12,6 (November): 927-955.

6 Warrick, Joby and Peter Finn. 2009. "Interviews Offer Look at Roles of CIA Contractors During

7 Interrogations." Washington Post. Sunday, July 19. Available at:

$8 \quad$ http://www.washingtonpost.com/wp-

$9 \quad$ dyn/content/article/2009/07/18/AR2009071802065_2.html?sid=ST2009071802309.

10 Woodward, Bob. 2002. Bush at War. New York: Simon \& Schuster.

11 Zelikow, P. (2012). "Codes of Conduct for a Twilight War." Houston Law Review 49:1-52.

12 http://www.houstonlawreview.org/wp-content/uploads/2012/05/1-Zelikow.pdf.

13

14

15

16 